\title{
Adjuvant ovarian function suppression and cognitive function in women with breast cancer
}

\author{
Kelly-Anne Phillips ${ }^{\star}, 1,2,3,4$, Meredith M Regan ${ }^{5,6}$, Karin Ribi ${ }^{7}$, Prudence A Francis ${ }^{1,2,3,4}$, Fabio Puglisi ${ }^{4,8,9}$, \\ Meritxell Bellet ${ }^{10,11}$, Simon Spazzapan ${ }^{4,12}$, Per Karlsson ${ }^{4,13}$, Daniel R Budman ${ }^{14,15}$, Khalil Zaman ${ }^{4,16}$, \\ Ehtesham A Abdi ${ }^{3,4,17}$, Susan M Domchek ${ }^{18,19}$, Yang Feng ${ }^{5}$, Karen N Price ${ }^{5,20}$, Alan S Coates ${ }^{3,4,21}$, \\ Richard D Gelber 5,20,22, Paul Maruff ${ }^{23}$, Frances Boyle $3,4,24$, John F Forbes ${ }^{4,25,26}$, Tim Ahles ${ }^{27,28,}$ \\ Gini F Fleming ${ }^{28,29}$ and Jürg Bernhard ${ }^{7,30}$ for the Co-SOFT investigators ${ }^{31}$
}

Background: To examine the effect on cognitive function of adjuvant ovarian function suppression (OFS) for breast cancer.

Methods: The Suppression of Ovarian Function (SOFT) trial randomised premenopausal women with hormone receptor-positive breast cancer to 5 years adjuvant endocrine therapy with tamoxifen + OFS, exemestane + OFS or tamoxifen alone. The Co-SOFT substudy assessed objective cognitive function and patient reported outcomes at randomisation (T0), and 1 year later (T1); the primary endpoint was change in global cognitive function, measured by the composite objective cognitive function score. Data were compared for the pooled tamoxifen + OFS and exemestane + OFS groups vs the tamoxifen alone group using the Wilcoxon rank-sum test.

Results: Of 86 participants, 74 underwent both T0 and T1 cognitive testing; 54 randomised to OFS + either tamoxifen (28) or exemestane (26) and 20 randomised to tamoxifen alone. There was no significant difference in the changes in the composite cognitive function scores between the OFS + tamoxifen or exemestane groups and the tamoxifen group (mean \pm s.d., $-0.21 \pm 0.92$ vs $-0.04 \pm 0.49$, respectively, $P=0.71$, effect size $=-0.20$ ), regardless of prior chemotherapy status, and adjusting for baseline characteristics.

Conclusions: The Co-SOFT study, although limited by small samples size, provides no evidence that adding OFS to adjuvant oral endocrine therapy substantially affects global cognitive function.

Adjuvant endocrine therapy with the selective oestrogen receptor modulator tamoxifen reduces mortality and has long been a standard of care for premenopausal women with potentially curable hormone receptor-positive breast cancer (Early Breast Cancer Trialists' Collaborative Group, 2005; Burstein et al, 2014). Two recent randomised trials, TEXT and Suppression of Ovarian Function Trial (SOFT), have shown that ovarian function suppression (OFS), in combination with either the aromatase inhibitor exemestane or tamoxifen, provides additional benefit over tamoxifen alone (Pagani et al, 2014; Francis et al, 2015). On the basis of these results, OFS will be increasingly used as part of the adjuvant treatment of premenopausal women with hormone receptor-positive breast cancer (Coates et al, 2015).

In choosing the most appropriate adjuvant endocrine therapy for an individual woman, side-effect profile is a major consideration (Hershman, 2015). It has been shown that women who experienced more side-effects required a greater survival benefit to accept adjuvant endocrine therapy (Thewes et al, 2005). Cognitive dysfunction is a much feared potential side-effect of breast cancer treatment (Haiken, 2015). Studies suggest that all components of

\footnotetext{
*Correspondence: K-A Phillips; E-mail: Kelly.Phillips@petermac.org

${ }^{31}$ The constituent members are listed before the References.
} 
cancer treatment may impair cognition (Janelsins et al, 2014) and that impairment may also be present in some women prior to cancer treatment (Scherling et al, 2012). It is clear that oestrogen has an important role in cognitive functioning (Sherwin, 2012) but few studies have examined the effect of adjuvant endocrine therapy for breast cancer on cognitive function (Phillips et al, 2010, 2011a,b; Schilder et al, 2010; Ganz et al, 2014) and none has assessed the impact of OFS. OFS results in very-low circulating oestrogen levels and some (Varney et al, 1993; Grigorova et al, 2006; Craig et al, 2007), but not all (Owens et al, 2002; Schmidt et al, 2013) data from non-oncological settings suggest that OFS with gonadotropin-releasing hormone agonists $(\mathrm{GnRH})$ agents impair cognition and that this impairment can be reversed with add-back oestrogen (Sherwin and Tulandi, 1996). It has also been reported that surgical menopause adversely affects cognition (Rocca et al, 2007; Ryan et al, 2014).

We conducted a cognitive function substudy of the SOFT. The primary objective of this Co-SOFT substudy was to compare changes in cognitive function, measured objectively over 1 year in premenopausal patients with breast cancer who received adjuvant endocrine therapy with OFS (either tamoxifen + OFS or exemestane + OFS) against those who received tamoxifen alone. It was hypothesised that, because of greater oestrogen deprivation, women who received OFS would have greater deterioration in cognitive function than those who received tamoxifen alone.

\section{MATERIALS AND METHODS}

The SOFT trial was an international, three-arm, non-blinded, randomised trial in premenopausal women with hormone receptor-positive breast cancer (Francis et al, 2015). It evaluated the efficacy of 5 years of adjuvant hormonal therapy using OFS plus tamoxifen or OFS plus exemestane or tamoxifen alone. Prior chemotherapy was allowed, provided women had premenopausal oestradiol levels after completing all chemotherapy and before enroling in the SOFT study. Women were stratified at randomisation according to whether they received adjuvant chemotherapy prior to randomisation, axillary lymph node status and intended initial method of OFS (women could choose between the GnRH agonist triptorelin, surgical oophorectomy or ovarian irradiation). Patients were enrolled within 12 weeks of their definitive breast cancer surgery or, for those who received chemotherapy, within 8 months of completing chemotherapy. Between November 2003 and January 2011, 3066 women were randomised on the SOFT trial.

Patients. To be eligible for the Co-SOFT substudy, women must have been registered for the SOFT study but not yet received any adjuvant endocrine therapy, and they must have been able to speak and write the local language fluently and have provided written informed consent. To minimise the potential for sampling bias, participating centres were to enrol all eligible patients. The substudy protocol was approved by the local and International Breast Cancer Study Group (IBCSG) ethics committees and the required health authorities of each participating centre.

Measures. At baseline before the start of protocol therapy (T0) and at $\sim 1$ year after randomisation to the SOFT study (T1) objective cognitive function was tested and patients provided selfreported data on cognitive function, psychological distress, fatigue, insomnia and quality of life.

Objective cognitive function. Objective cognitive function was measured with the CogState computerised test battery (CogState Ltd; http://www.cogstate.com); a brief test designed specifically for repeated application and free from practice effects (Falleti et al, 2003; Silbert et al, 2004; Vardy et al, 2006). Testing consisted of five non-verbal tasks, measuring the speed of psychomotor function, visual attention, attention and working memory, and visual learning and memory. In addition, two verbal learning and memory tasks required subjects to learn a 12-word shopping list, and then to recall this list after 20 minutes (Table 1). Details of the test battery have been described elsewhere (Phillips et al, 2010). For the seven tasks, a composite score, representing the age-adjusted average standardised score of each task for each individual, was calculated (Phillips et al, 2010). This provides a measure of global cognitive function that has been validated psychometrically (Maruff et al, 2009) and empirically in studies of pharmacological agents (Snyder et al, 2005; Maruff et al, 2006), head injury (Collie et al, 2001), fatigue (Falleti et al, 2003) and surgery (Silbert et al, 2004).

Patient reported outcomes. After cognitive testing, women completed several questionnaires. Self-reported cognitive function was assessed by the Cognitive Failures Questionnaire (CFQ) (Broadbent et al, 1982), a 25-item questionnaire that assesses the frequency of failures in memory, perception and motor function over the past 6 months. To measure psychological distress, a 12-item version of the General Health Questionnaire (Goldberg and Williams, 2000) was used. In addition, the Brief Fatigue Inventory (Mendoza et al, 1999), a nine-item instrument to assess severity of fatigue and its inference with daily living in a $24 \mathrm{~h}$ period, was administered. Global quality of life domains (physical well-being, mood, coping effort, subjective health estimation) as well as symptom-specific quality of life domains (nausea and vomiting, appetite, tiredness, hot flushes, restriction in arm movements and insomnia) were measured by linear analogue self-assessment indicators (Bernhard et al, 2015). Validated language versions were used where available, otherwise a standard translation procedure was performed (forward-backward).

Statistical considerations. The protocol-specified primary comparison was the change in the composite score of the CogState tasks over 1 year for women randomised to tamoxifen + OFS vs tamoxifen alone. Due to low accrual to the substudy, this was modified, prior to any analysis, to compare the pooled tamoxifen

\section{Table 1. Tasks and cognitive domains assessed by the CogState battery}

\begin{tabular}{|l|l|l|l|}
\hline Task & Cognitive Domain Assessed & Type of test & Unit of measurement \\
\hline Detection & Speed of psychomotor function & Performance speed & Performance speed \\
\hline Identification & Visual attention & Performance speed & Log 10 milliseconds \\
\hline Monitoring & Visual attention & Performance accuracy & Log 10 milliseconds \\
\hline Memory & Attention and working memory & Performance accuracy & Arcsine proportion correct \\
\hline Learning & Visual learning and memory & Performance accuracy & Performance accuracy \\
\hline ISLT & Verbal learning and memory & & Total number correct \\
\hline Delayed ISLT & Verbal learning and memory & & Total number correct \\
\hline Abbreviation: ISLT $=$ International Shopping List Test. &
\end{tabular}


+ OFS and exemestane + OFS groups with the tamoxifen alone group. The observed sample size provided $80 \%$ power to detect an effect size of 0.76 with two-sided $\alpha=0.05$. Cognitive test scores were transformed (Phillips et al, 2010), standardised according to agespecific norms, and the resulting $Z$-scores averaged to calculate the composite score (Maruff et al, 2009). Individual $Z$-scores more than 1.96 s.d. below the norm were defined as 'impaired.' The change in composite scores between $\mathrm{T} 0$ and $\mathrm{T} 1$ were calculated; a negative change in composite score indicated deterioration in cognitive function. Changes in composite score and individual tasks were compared between treatment groups using Wilcoxon rank-sum tests. Effect sizes for the comparison of treatments were calculated as mean change in OFS groups minus mean change in tamoxifen alone group divided by the pooled s.d. of the change (Cohen, 1988) for the composite score and each task. According to convention, effect sizes of +0.2 was considered small, +0.5 moderate and +0.8 large (Cohen, 1988). Sensitivity analyses compared treatment groups using regression modelling, adjusting for patient, disease and treatment characteristics at baseline: language and treatment assignment, age, family history of breast cancer, body mass index, menstruation status, history and/or treatment of anxiety/depression, nodal status and prior chemotherapy and use of HER2-targeted treatment. Characteristics were compared between treatment groups using Fisher's exact tests. Spearman's correlation coefficients were calculated between composite score and patient-reported outcome measures.

\section{RESULTS}

Co-SOFT commenced recruitment in October 2007 and after 26 Co-SOFT centres were activated, 86 of 102 (84\%) eligible women enrolled in SOFT and with no prior endocrine therapy were recruited. Planned accrual was 321 patients but Co-SOFT was closed in January 2011 because the SOFT trial had completed accrual. Patient, demographic, medical, disease and treatment characteristics were similar between those eligible women at participating centres who did and those eligible women who did not participate in Co-SOFT (data not shown). Of 86 Co-SOFT participants, 74 underwent both $\mathrm{T} 0$ and $\mathrm{T} 1$ cognitive function testing and were included in the primary analysis (8 withdrew consent or declined assessment, 4 missed testing for administrative reasons). Of the 74 evaluable patients, 54 were randomised to OFS + oral endocrine therapy (OFS + tamoxifen $n=28$ or OFS + exemestane $n=26$ ) and 20 were randomised to tamoxifen alone (Figure 1).

As shown in Table 2, baseline characteristics were well-balanced between the two groups. During the first year 49 women had GnRH agonist alone for OFS, 4 had GnRH followed by oophorectomy and 1 had oophorectomy.

Figure 2 shows the change in objective cognitive function between $\mathrm{T} 0$ and $\mathrm{T} 1$ by study treatment assignment. There was no significant difference in the changes in the CogState composite scores from $\mathrm{T} 0$ to $\mathrm{T} 1$ for patients randomised to OFS + oral endocrine therapy compared with tamoxifen alone (mean \pm s.d., $-0.21 \pm 0.92$ vs $-0.04 \pm 0.49$, respectively, $P=0.71$, effect size $=$ $-0.20)$. This was true regardless of whether women had received prior chemotherapy, and adjusting for baseline characteristics. Women who received OFS showed greater deterioration in the International Shopping List Task (ISLT) than those who received tamoxifen alone (mean \pm s.d. $-0.20 \pm 0.68$ vs $0.29 \pm 0.73$ respectively, $P=0.02$, effect size $=-0.68$ ). For the other six tasks there were small effect sizes and no statistically significant difference between the two treatment groups.

Table 3 shows the number of women that met the definition for impairment on each cognitive task at each timepoint. The task for which the largest proportion of women changed from normal to

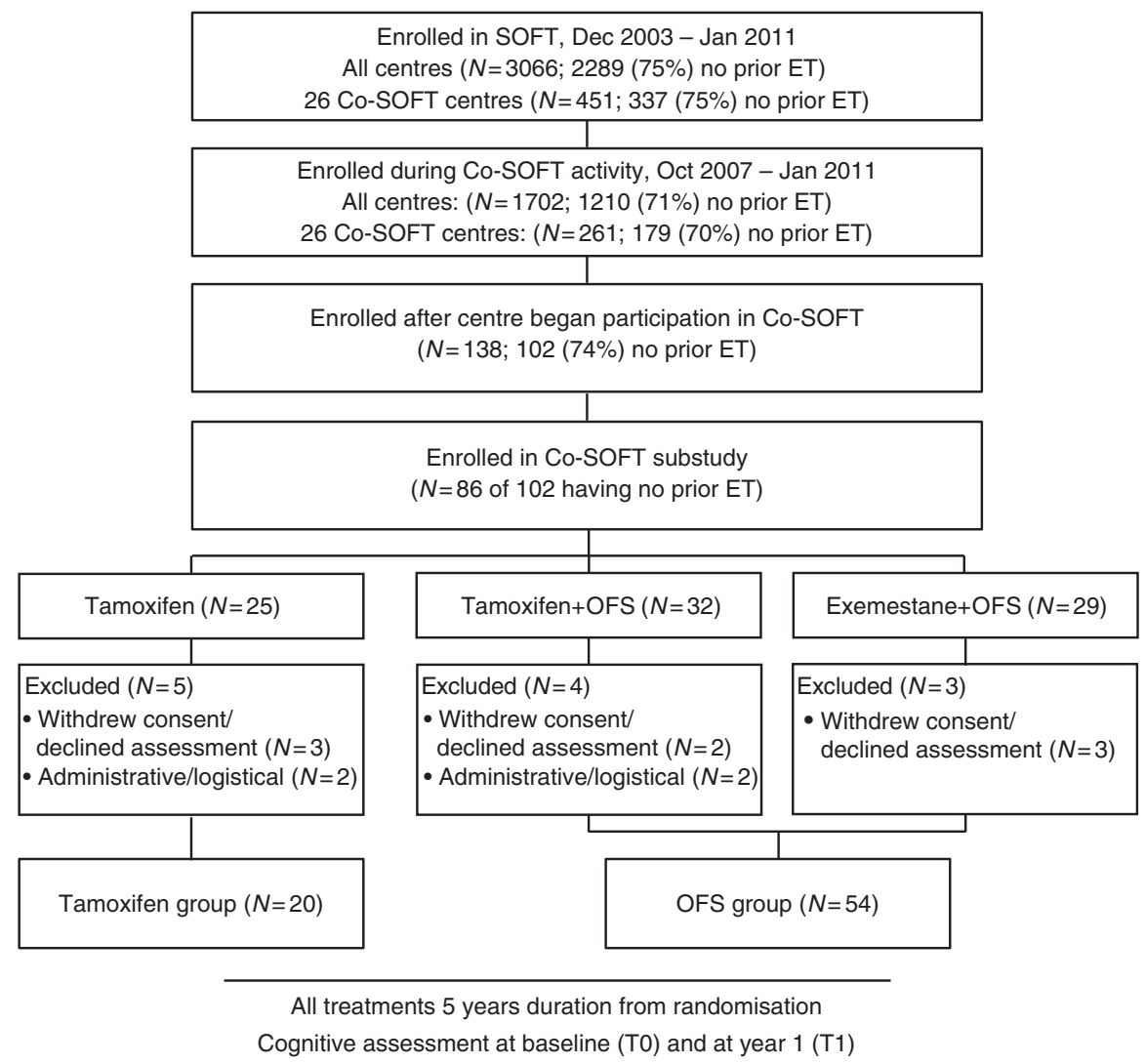

Figure 1. CONSORT Flow Diagram showing the design and enrolment to the Co-SOFT substudy. Eligible patients were enrolled in the substudy at the time of randomisation to SOFT. ET=endocrine therapy. 
Table 2. Patient, disease and treatment characteristics at TO

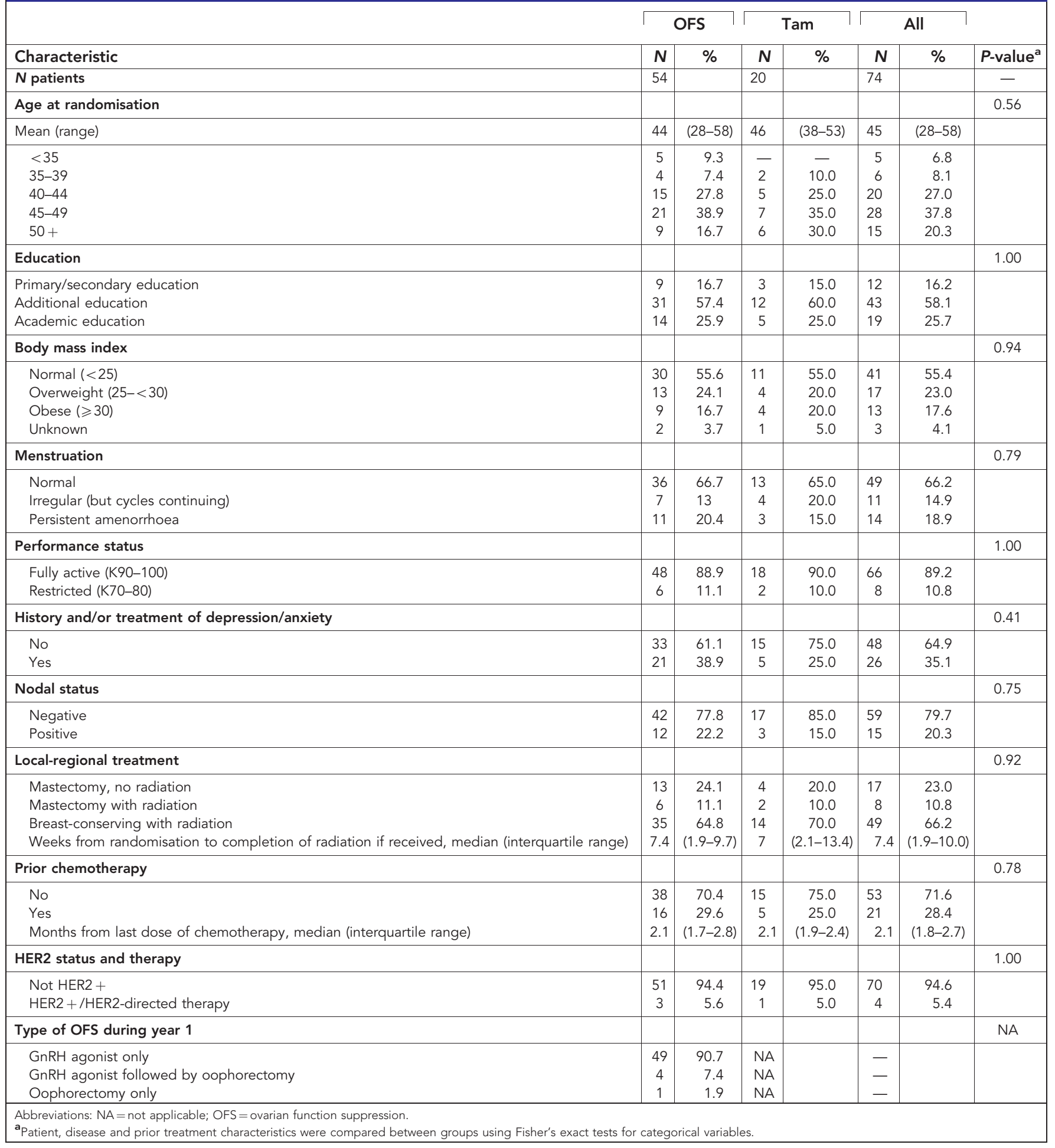

impaired status between T0 and T1 was the learning task; for which $22 \%$ of those on OFS and $15 \%$ of those on tamoxifen went from normal to impaired and conversely $7 \%$ of those on OFS and $20 \%$ of those on tamoxifen went from impaired to normal. It has to be noted that the numbers in the various subgroups are too small for a conclusive interpretation.

Table 4 shows the patient reported outcome data. The change in self-reported cognitive function between T0 and T1 indicated greater decline in patients receiving OFS $v s$ those receiving tamoxifen alone (mean \pm s.d., $7.8 \pm 13.1$ vs 1.1 \pm 9.7, effect size $=0.53)$. Note that higher CFQ scores indicate worse self- reported cognitive function, thus a positive change score indicates deterioration. No correlation was observed between objective cognitive function (CogState composite cognitive function score) and self-reported cognitive function $(r=-0.12)$, fatigue $(r=-0.05)$, psychologic distress $(r=0.06)$ or quality of life indicators (range, $r=-0.09$ to 0.16 ) including insomnia $(r=0.11)$, at year 1 . However, self-reported cognitive function was moderately and positively correlated with fatigue $(r=0.55)$ and psychologic distress $(r=0.53)$ and was low to moderately correlated with quality of life indicators (range, $r=-0.13$ to $-0.45)$, including insomnia $(r=-0.31)$, at year 1 . 


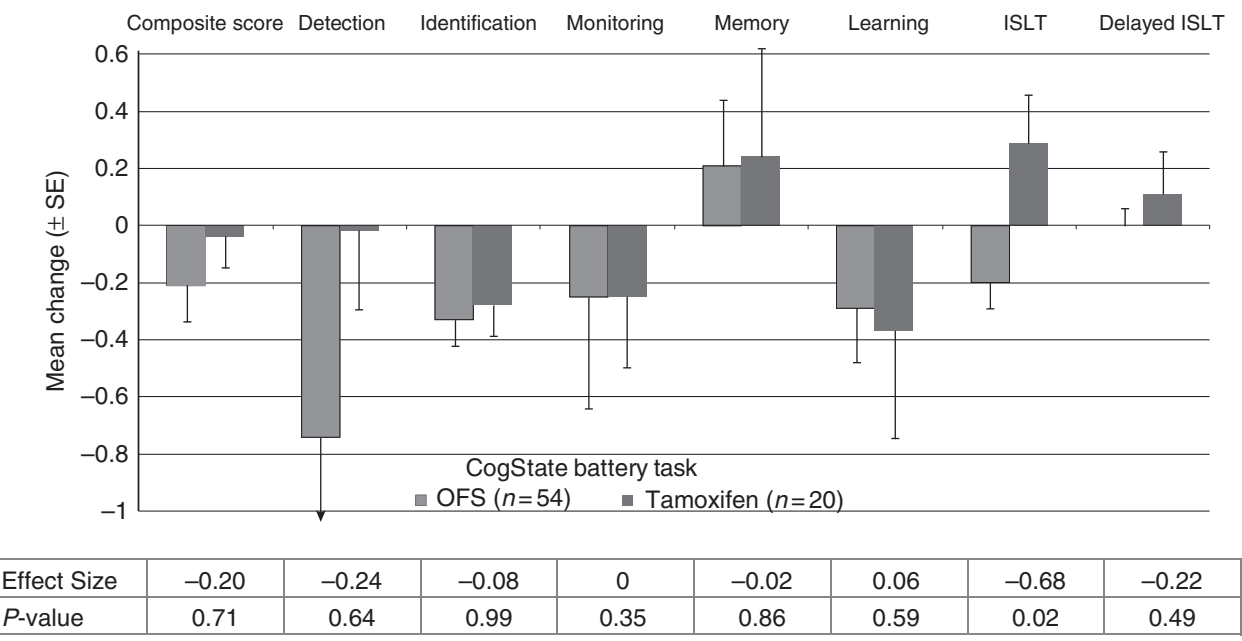

Figure 2. Mean change in CogState test performance between TO (baseline) and T1 (one year) according to treatment assignment for the composite score and the seven cognitive tasks assessed by the CogState battery. A negative change in individual task or composite score indicates deterioration in cognitive function. ISLT, international shopping list test.

\section{Table 3. Normal/Impaired CogState task scores according to treatment assignment}

\begin{tabular}{|c|c|c|c|c|c|c|c|c|}
\hline \multirow[b]{2}{*}{ Task } & \multicolumn{2}{|c|}{$\begin{array}{c}\text { Normal T0 \& Normal T1 } \\
N(\%)\end{array}$} & \multicolumn{2}{|c|}{\begin{tabular}{|c|} 
Impaired T0 \& Impaired T1 \\
$N(\%)$
\end{tabular}} & \multicolumn{2}{|c|}{$\begin{array}{c}\text { Normal T0 } \rightarrow \text { Impaired T1 } \\
N(\%)\end{array}$} & \multicolumn{2}{|c|}{$\begin{array}{c}\text { Impaired T0 } \rightarrow \text { Normal T1 } \\
N(\%)\end{array}$} \\
\hline & Tam & OFS & Tam & OFS & Tam & OFS & Tam & OFS \\
\hline Identification & $18(90)$ & $53(98)$ & $0(0)$ & $0(0)$ & $2(10)$ & $0(0)$ & $0(0)$ & 1(2) \\
\hline Monitoring & $18(90)$ & $45(83)$ & $0(0)$ & $3(6)$ & $2(10)$ & $2(4)$ & $0(0)$ & $4(7)$ \\
\hline ISLT & $19(95)$ & $52(96)$ & $0(0)$ & $0(0)$ & $0(0)$ & $0(0)$ & $0(0)$ & $0(0)$ \\
\hline Delayed ISLT & $20(100)$ & $53(98)$ & $0(0)$ & $0(0)$ & $0(0)$ & $0(0)$ & $0(0)$ & $0(0)$ \\
\hline
\end{tabular}

\section{Table 4. Patient reported outcomes data}

\begin{tabular}{|c|c|c|c|c|c|c|}
\hline \multirow{2}{*}{ Patient Reported Outcome } & \multicolumn{2}{|c|}{ TO } & \multicolumn{2}{|c|}{ T1 } & \multicolumn{2}{|c|}{ Change from T0 to T1 } \\
\hline & Tam & OFS & Tam & OFS & Tam & OFS \\
\hline General Health Questionnaire -12 & $25.7(5.1)$ & $24.5(4.8)$ & $23.7(4.9)$ & $25.3(6.6)$ & $-2.1(5.2)$ & $0.9(5.9)$ \\
\hline Brief Fatigue Inventory & $3.2(2.3)$ & $2.9(1.8)$ & $3.0(2.2)$ & $3.7(2.2)$ & $-0.1(1.9)$ & $0.7(2.3)$ \\
\hline Tiredness & $62(26)$ & $59(31)$ & $57(28)$ & $50(29)$ & $-5(37)$ & $-9(33)$ \\
\hline Appetite & $75(25)$ & $81(21)$ & $85(17)$ & $80(21)$ & $10(32)$ & $-2(24)$ \\
\hline Hot Flushes & $83(23)$ & $84(27)$ & $62(29)$ & $41(30)$ & $-21(32)$ & $-42(37)$ \\
\hline Nausea and Vomiting & $89(21)$ & $94(14)$ & $82(25)$ & $91(17)$ & $-6(37)$ & $-3(19)$ \\
\hline
\end{tabular}




\section{DISCUSSION}

The study results do not provide evidence that the addition of OFS to oral adjuvant endocrine therapy for breast cancer affects objective global cognitive function in a clinically meaningful way over 1 year of endocrine treatment. However, the study did not have adequate power to detect a small to moderate effect on cognitive function. The only cognitive task for which performance of women randomised to OFS deteriorated significantly more than those randomised to tamoxifen alone was a test of verbal learning and memory, the ISLT. Some studies have suggested that verbal memory is particularly affected by OFS in non-oncological settings (Craig et al, 2007); however, we did not find a difference between the OFS and tamoxifen alone groups in terms of amount of deterioration in another measure of verbal memory, the delayed ISLT.

Previous studies in this field have focussed on tamoxifen and the aromatase inhibitors, nevertheless the impact of these drugs on cognitive function remains poorly understood (Buwalda and Schagen, 2013). Most studies have been observational, with important differences between treatment groups that limits the interpretation of associations of particular endocrine treatments with cognitive changes. One randomised study tested postmenopausal patients before and 1 year after commencing endocrine therapy and compared those randomised to tamoxifen treatment with those randomised to the aromatase inhibitor exemestane and also included a healthy control group (Schilder et al, 2010). It revealed that women randomised to tamoxifen had worse information processing speed after one year compared with those randomised to exemestane. In the non-randomised comparison with healthy controls exemestane did not seem to impact cognitive function adversely. The lack of impact of aromatase inhibitors on cognitive function is also supported by the results of the cognitive function substudy of the randomised IBIS II chemoprevention trial, which showed that postmenopausal women randomised to the aromatase inhibitor anastrozole had similar cognitive function after 2 years compared with those randomised to placebo (Jenkins et al, 2008). Similarly in the randomised BIG 1-98 study, postmenopausal women taking the aromatase inhibitor letrozole during year 5 of adjuvant endocrine therapy had better global cognitive function than those taking tamoxifen (Phillips et al, 2010) and cognitive function in both groups improved after cessation of adjuvant endocrine therapy (Phillips et al, 2011a).

Although no previous study has examined the impact of adjuvant OFS on cognitive function, several studies have attempted to assess the impact of chemotherapy-induced premature ovarian insufficiency with mixed results (Jenkins et al, 2006; Schagen et al, 2006; Hermelink et al, 2008; Vearncombe et al, 2011). Recently a longitudinal neuroimaging study showed that women who had chemotherapy-induced amenorrhoea showed increases in brain activation from pre to post-chemotherapy, suggesting compensatory neural activation; no increases were seen in women who did not have chemotherapy-induced amenorrhoea or healthy controls (Conroy et al, 2013).

In our study, there was greater deterioration in self-reported cognitive function in the OFS group compared with the group that received tamoxifen alone. This was an unplanned exploratory analysis and needs further prospective evaluation; however, many previous studies have found that subjective cognitive complaints are often worse than would be expected from objective cognitive function testing (Hutchinson et al, 2012). There are several possible explanations for this discrepancy, but studies that have incorporated functional brain imaging suggest that patients that complain of cognitive dysfunction may reach normal performance on objective cognitive function tests by activating other brain areas not usually directly related to the cognitive task, and this may be perceived as greater effort (Hutchinson et al, 2012). Our finding that self-reported cognitive function was moderately correlated with fatigue and psychologic distress is consistent with most previous studies (Hutchinson et al, 2012).

The strengths of our study include the longitudinal design with a well-defined and homogenous sample of SOFT patients who had not commenced endocrine therapy, defined type and duration of endocrine therapy that was randomly assigned and the ability to control for potential confounding factors. Small sample size is the main limitation of our study, which resulted in limited power to detect a small, but potentially meaningful, effect, as might be anticipated when comparing two groups of patients receiving endocrine therapies. There is potential for sampling bias, as substudy centres enrolled only $84 \%$ of eligible patients, and the possibility that the treatment assignment was part of the decision cannot be excluded. In the future, consideration perhaps should be given to incorporating measures of cognitive function in the main study protocol, as is often done for quality of life measures, in order to avoid having uninformative data on the effects of new treatments on cognition. Other limitations include the absence of a control group not treated with any endocrine therapy and the lack of hormone testing to confirm the functional gonadal status of the women, particularly those in the tamoxifen arm, some of whom may have had chemotherapy-induced hypogonadism at T1. Also, our cognitive function test battery did not include a measure of verbal fluency and cognitive function was assessed only over the first year of adjuvant endocrine therapy, which perhaps allowed time for development of some compensation for any cognitive dysfunction related to the endocrine therapy.

Given the importance of this clinical question for women, the strong biological basis for a potential effect of OFS on cognitive function, and the limitations of our study, we believe further study of the impact of adjuvant OFS on cognitive function in breast cancer patients is warranted.

\section{ACKNOWLEDGEMENTS}

We thank the patients who participated and the staff who conducted the study at the participating centres. We also thank the ANZBCTG Trials Coordination Department staff Lauren Boyes, Ingrid Laycock, Annette Dempsey and Dianne Lindsay and the International Breast Cancer Study Group (IBCSG) Coordinating and Data Management Centres for their help with the conduct of this study. The Co-SOFT study was funded by the Australian National Health and Medical Research Council (\#454507) and the Breast Cancer Institute of Australia, the Fund Raising Department of the Australia and New Zealand Breast Cancer Trials Group (ANZBCTG); US NIH SU10CA-035279-30 to DRB. KAP is an Australian National Breast Cancer Foundation Fellow. Support for the IBCSG: Frontier Science and Technology Research Foundation, Swiss Group for Clinical Cancer Research (SAKK), US National Cancer Institute (NCI) (CA75362) to MMR, Swiss Cancer Research/Oncosuisse. Grant support for participating cooperative groups for the SOFT Trial: Australia and New Zealand Breast Cancer Trials Group (NHMRC 351161 and 510788); SWOG (US NIH CA32102); Alliance (US NIH U10-CA180821); ECOGACRIN (US NIH CA21115 and CA16116); NSABP/NRG (US NIH U10-CA-12027, U10-CA-69651, U10-CA-37377, U10-CA-69974); NCIC (US NIH CA077202 and CCSRI 015469 and 021039). The SOFT trial receives financial support for trial conduct from Pfizer, and drug supply from Pfizer and Ipsen. P.M. is a full time employee of Cogstate, Ltd. PAF has provided unpaid consultancy and an unpaid overseas presentation regarding the results of the SOFT trial for Pfizer. The IBCSG Statistical Center (MMR, YF, $\mathrm{RDG}, \mathrm{KNP}$ ) has received research support from Pfizer and Ipsen in support of SOFT and TEXT. 


\section{CONFLICT OF INTEREST}

The authors declare no conflict of interest.

\section{REFERENCES}

Bernhard J, Luo W, Ribi K, Colleoni M, Burstein HJ, Tondini C, Pinotti G, Spazzapan S, Ruhstaller T, Puglisi F, Pavesi L, Parmar V, Regan MM, Pagani O, Fleming GF, Francis PA, Price KN, Coates AS, Gelber RD, Goldhirsch A, Walley BA (2015) Patient-reported outcomes with adjuvant exemestane versus tamoxifen in premenopausal women with early breast cancer undergoing ovarian suppression (TEXT and SOFT): a combined analysis of two phase 3 randomised trials. Lancet Oncol 16(7): 848-858.

Broadbent DE, Cooper PF, FitzGerald P, Parkes KR (1982) The Cognitive Failures Questionnaire (CFQ) and its correlates. Br J Clin Psychol 21(Pt 1): $1-16$.

Burstein HJ, Temin S, Anderson H, Buchholz TA, Davidson NE, Gelmon KE, Giordano SH, Hudis CA, Rowden D, Solky AJ, Stearns V, Winer EP, Griggs JJ (2014) Adjuvant endocrine therapy for women with hormone receptor-positive breast cancer: american society of clinical oncology clinical practice guideline focused update. J Clin Oncol 32(21): 2255-2269.

Buwalda B, Schagen SB (2013) Is basic research providing answers if adjuvant anti-estrogen treatment of breast cancer can induce cognitive impairment? Life Sci 93(17): 581-588.

Coates AS, Winer EP, Goldhirsch A, Gelber RD, Gnant M, Piccart-Gebhart M, Thurlimann B, Senn HJ, Panel M (2015) Tailoring therapies-improving the management of early breast cancer: St Gallen International Expert Consensus on the Primary Therapy of Early Breast Cancer 2015. Ann Oncol 26(8): 1533-1546.

Cohen J (1988) Statistical Power Analysis for the Behavioural Sciences, 2nd ed. Erlbaum: Hillsdale, NJ, USA.

Collie A, Darby D, Maruff P (2001) Computerised cognitive assessment of athletes with sports related head injury. Br J Sports Med 35(5): 297-302.

Conroy SK, McDonald BC, Ahles TA, West JD, Saykin AJ (2013) Chemotherapy-induced amenorrhea: a prospective study of brain activation changes and neurocognitive correlates. Brain Imaging Behav 7(4): 491-500.

Craig MC, Fletcher PC, Daly EM, Rymer J, Cutter WJ, Brammer M, Giampietro V, Wickham H, Maki PM, Murphy DG (2007) Gonadotropin hormone releasing hormone agonists alter prefrontal function during verbal encoding in young women. Psychoneuroendocrinology 32(8-10): $1116-1127$

Early Breast Cancer Trialists' Collaborative Group (2005) Effects of chemotherapy and hormonal therapy for early breast cancer on recurrence and 15-year survival: an overview of the randomised trials. Lancet 365(9472): 1687-1717.

Falleti MG, Maruff P, Collie A, Darby DG, McStephen M (2003) Qualitative similarities in cognitive impairment associated with $24 \mathrm{~h}$ of sustained wakefulness and a blood alcohol concentration of $0.05 \%$. J Sleep Res 12(4): 265-274.

Francis PA, Regan MM, Fleming GF, Láng I, Ciruelos E, Bellet M, Bonnefoi HR, Climent MA, Da Prada GA, Burstein HJ, Martino S, Davidson NE, Geyer Jr CE, Walley BA, Coleman R, Kerbrat P, Buchholz S, Ingle JN, Winer EP, Rabaglio-Poretti M, Maibach R, Ruepp B, Giobbie-Hurder A, Price KN, Colleoni M, Viale G, Coates AS, Goldhirsch A, Gelber RD, SOFT Investigators and the International Breast Cancer Study Group (2015) Adjuvant ovarian suppression in premenopausal breast cancer. N Engl J Med 372(17): 1673.

Ganz PA, Petersen L, Castellon SA, Bower JE, Silverman DH, Cole SW, Irwin MR, Belin TR (2014) Cognitive function after the initiation of adjuvant endocrine therapy in early-stage breast cancer: an observational cohort study. J Clin Oncol 32(31): 3559-3567.

Goldberg D, Williams P (2000) General Health Questionnaire (GHQ). nferNelson: Swindon, Wiltshire, UK.

Grigorova M, Sherwin BB, Tulandi T (2006) Effects of treatment with leuprolide acetate depot on working memory and executive functions in young premenopausal women. Psychoneuroendocrinology 31(8): 935-947.

Haiken (2015) 'Chemo Brain' Can Be a Serious Concern for Cancer Patients. 2015. Available at https://www.caring.com/blogs/caring-currents/ chemo-brain-can-be-a-serious-concern-for-cancer-patients.
Hermelink K, Henschel V, Untch M, Bauerfeind I, Lux MP, Munzel K (2008) Short-term effects of treatment-induced hormonal changes on cognitive function in breast cancer patients: results of a multicenter, prospective, longitudinal study. Cancer 113(9): 2431-2439.

Hershman DL (2015) Perfecting breast-cancer treatment-incremental gains and musculoskeletal pains. $N$ Engl J Med 372(5): 477-478.

Hutchinson AD, Hosking JR, Kichenadasse G, Mattiske JK, Wilson C (2012) Objective and subjective cognitive impairment following chemotherapy for cancer: a systematic review. Cancer Treat Rev 38(7): 926-934.

Janelsins MC, Kesler SR, Ahles TA, Morrow GR (2014) Prevalence, mechanisms, and management of cancer-related cognitive impairment. Int Rev Psychiatry 26(1): 102-113.

Jenkins V, Shilling V, Deutsch G, Bloomfield D, Morris R, Allan S, Bishop H, Hodson N, Mitra S, Sadler G, Shah E, Stein R, Whitehead S, Winstanley J (2006) A 3-year prospective study of the effects of adjuvant treatments on cognition in women with early stage breast cancer. Br J Cancer 94(6): 828-834.

Jenkins VA, Ambroisine LM, Atkins L, Cuzick J, Howell A, Fallowfield LJ (2008) Effects of anastrozole on cognitive performance in postmenopausal women: a randomised, double-blind chemoprevention trial (IBIS II). Lancet Oncol 9(10): 953-961.

Maruff P, Thomas E, Cysique L, Brew B, Collie A, Snyder P, Pietrzak RH (2009) Validity of the CogState brief battery: relationship to standardized tests and sensitivity to cognitive impairment in mild traumatic brain injury, schizophrenia, and AIDS dementia complex. Arch Clin Neuropsychol 24(2): 165-178.

Maruff P, Werth J, Giordani B, Caveney AF, Feltner D, Snyder PJ (2006) A statistical approach for classifying change in cognitive function in individuals following pharmacologic challenge: an example with alprazolam. Psychopharmacology (Berl) 186(1): 7-17.

Mendoza TR, Wang XS, Cleeland CS, Morrissey M, Johnson BA, Wendt JK, Huber SL (1999) The rapid assessment of fatigue severity in cancer patients: use of the Brief Fatigue Inventory. Cancer 85(5): 1186-1196.

Owens JF, Matthews KA, Everson SA (2002) Cognitive function effects of suppressing ovarian hormones in young women. Menopause 9(4): 227-235.

Pagani O, Regan MM, Walley BA, Fleming GF, Colleoni M, Lang I, Gomez HL, Tondini C, Burstein HJ, Perez EA, Ciruelos E, Stearns V, Bonnefoi HR, Martino S, Geyer Jr. CE, Pinotti G, Puglisi F, Crivellari D, Ruhstaller T, Winer EP, Rabaglio-Poretti M, Maibach R, Ruepp B, Giobbie-Hurder A, Price KN, Bernhard J, Luo W, Ribi K, Viale G, Coates AS, Gelber RD, Goldhirsch A, Francis PA. Textand SOFT InvestigatorsInternational Breast Cancer Study Group (2014) Adjuvant exemestane with ovarian suppression in premenopausal breast cancer. N Engl J Med 371(2): 107-118.

Phillips KA, Aldridge J, Ribi K, Sun Z, Thompson A, Harvey V, Thurlimann B, Cardoso F, Pagani O, Coates AS, Goldhirsch A, Price KN, Gelber RD, Bernhard J (2011a) Cognitive function in postmenopausal breast cancer patients one year after completing adjuvant endocrine therapy with letrozole and/or tamoxifen in the BIG 1-98 trial. Breast Cancer Res Treat 126(1): 221-226.

Phillips KA, Ribi K, Fisher R (2011b) Do aromatase inhibitors have adverse effects on cognitive function? Breast Cancer Res 13(1): 203.

Phillips KA, Ribi K, Sun Z, Stephens A, Thompson A, Harvey V, Thurlimann B, Cardoso F, Pagani O, Coates AS, Goldhirsch A, Price KN, Gelber RD, Bernhard J (2010) Cognitive function in postmenopausal women receiving adjuvant letrozole or tamoxifen for breast cancer in the BIG 1-98 randomized trial. Breast 19(5): 388-395.

Rocca WA, Bower JH, Maraganore DM, Ahlskog JE, Grossardt BR, de Andrade M, Melton 3rd LJ (2007) Increased risk of cognitive impairment or dementia in women who underwent oophorectomy before menopause. Neurology 69(11): 1074-1083.

Ryan J, Scali J, Carriere I, Amieva H, Rouaud O, Berr C, Ritchie K, Ancelin ML (2014) Impact of a premature menopause on cognitive function in later life. BJOG 121(13): 1729-1739.

Schagen SB, Muller MJ, Boogerd W, Mellenbergh GJ, van Dam FS (2006) Change in cognitive function after chemotherapy: a prospective longitudinal study in breast cancer patients. J Natl Cancer Inst 98(23): $1742-1745$.

Scherling C, Collins B, Mackenzie J, Bielajew C, Smith A (2012) Prechemotherapy differences in response inhibition in breast cancer patients compared to controls: a functional magnetic resonance imaging study. J Clin Exp Neuropsychol 34(5): 543-560. 
Schilder CM, Seynaeve C, Beex LV, Boogerd W, Linn SC, Gundy CM, Huizenga HM, Nortier JW, van de Velde CJ, van Dam FS, Schagen SB (2010) Effects of tamoxifen and exemestane on cognitive functioning of postmenopausal patients with breast cancer: results from the neuropsychological side study of the tamoxifen and exemestane adjuvant multinational trial. J Clin Oncol 28(8): 1294-1300.

Schmidt PJ, Keenan PA, Schenkel LA, Berlin K, Gibson C, Rubinow DR (2013) Cognitive performance in healthy women during induced hypogonadism and ovarian steroid addback. Arch Womens Ment Health 16(1): 47-58.

Sherwin BB (2012) Estrogen and cognitive functioning in women: lessons we have learned. Behav Neurosci 126(1): 123-127.

Sherwin BB, Tulandi T (1996) 'Add-back' estrogen reverses cognitive deficits induced by a gonadotropin-releasing hormone agonist in women with leiomyomata uteri. J Clin Endocrinol Metab 81(7): 2545-2549.

Silbert BS, Maruff P, Evered LA, Scott DA, Kalpokas M, Martin KJ, Lewis MS, Myles PS (2004) Detection of cognitive decline after coronary surgery: a comparison of computerized and conventional tests. Br J Anaesth 92(6): 814-820.

Snyder PJ, Werth J, Giordani B, Caveney AF, Feltner D, Maruff P (2005) A method for determining the magnitude of change across different cognitive functions in clinical trials: the effects of acute administration

\section{APPENDIX}

\section{Participating Centres and Principal Investigators}

Australia and New Zealand Breast Cancer Trials Group (ANZBCTG), Australia; Prof. John Forbes, Dianne Lindsay, Lauren Boyes Calvary Mater Newcastle, Waratah, New South Wales; A van der Westhuizen

Maroondah Hospital, Ringwood East, Victoria; J Chirgwin

Peter MacCallum Cancer Center, East Melbourne, Victoria; PA Francis

Royal Hobart Hospital, Hobart, Tasmania; D Boadle

St John of God Hospital, Bunbury, Western Australia; M Buck

St Vincents Hospital, Fitzroy, Victoria; R Snyder

The Mater Hospital, North Sydney, New South Wales; F Boyle

The Tweed Hospital, Tweed Heads, New South Wales; E Abdi

\section{Italy}

Centro di Riferimento Oncologico, Aviano; D Crivellari

Dipartimento di Oncologia, Azienda Ospedaliero-Universitaria di Udine, Udine; F Puglisi

\section{Sweden}

Sahlgrenska University Hospital, Gothenburg; P Karlsson

Swiss Association for Clinical Cancer Research (SAKK), Switzerland Centre Hospitalier Universitaire Vaudois, Lausanne; K Zaman of two different doses alprazolam. Hum Psychopharmacol 20(4): 263-273.

Thewes B, Meiser B, Duric VM, Stockler MR, Taylor A, Stuart-Harris R, Links M, Wilcken N, McLachlan SA, Phillips KA, Beith J, Boyle F, Friedlander ML (2005) What survival benefits do premenopausal patients with early breast cancer need to make endocrine therapy worthwhile? Lancet Oncol 6(8): 581-588.

Vardy J, Wong K, Yi QL, Park A, Maruff P, Wagner L, Tannock IF (2006) Assessing cognitive function in cancer patients. Support Care Cancer 14(11): 1111-1118.

Varney NR, Syrop C, Kubu CS, Struchen M, Hahn S, Franzen K (1993) Neuropsychologic dysfunction in women following leuprolide acetate induction of hypoestrogenism. J Assist Reprod Genet 10(1): 53-57.

Vearncombe KJ, Rolfe M, Andrew B, Pachana NA, Wright M, Beadle G (2011) Cognitive effects of chemotherapy-induced menopause in breast cancer. Clin Neuropsychol 25(8): 1295-1313.

This work is published under the standard license to publish agreement. After 12 months the work will become freely available and the license terms will switch to a Creative Commons AttributionNonCommercial-Share Alike 4.0 Unported License.

\section{Spain}

Hospital Universitari Vall D’ Hebron, Barcelona; M Bellet

\section{Belgium}

U.Z. Gasthuisberg, Leuven; P Neven

Canada

Ottawa Hospital Research Institute, Ottawa, Ontario; SF Dent BCCA Cancer Center for the Southern Interior, Kelowna, British Columbia; S. Ellard

\section{United States of America}

Mercy General Hospital, Carmichael, CA; M Javeed Front Range Cancer Specialists, Fort Collins, CO; D Medgyesy Norwalk Hospital, Norwalk, CT; RC Frank Dekalb Medical Center, Atlanta, GA; TE Seay Northern Indiana Consortium, South Bend, IN; RH Ansari Mission Hospitals Inc, Asheville, NC; MJ Messino Northeast Medical Center, Concord, NC; JG Wall New Hampshire Oncology-Hematology Associates, Concord, NH; C Catcher North Shore University Hospital, Manhasset, NY; DR Budman Abramson Cancer Center of the University of Pennsylvania, Philadelphia, PA; SM Domchek 
${ }^{1}$ Division of Cancer Medicine, Peter MacCallum Cancer Centre, St Andrew's Place, East Melbourne, VIC 3002, Australia; ${ }^{2}$ Sir Peter MacCallum Department of Oncology, The University of Melbourne, Grattan Street, Parkville, VIC 3010, Australia; ${ }^{3}$ Australia and New Zealand Breast Cancer Trials Group (ANZBCTG), Platt Street, Waratah, NSW 2298, Australia; ${ }^{4}$ nternational Breast Cancer Study Group, Bern CH-3008, Switzerland; 5 International Breast Cancer Study Group Statistical Center, Department of Biostatistics and Computational Biology, Dana-Farber Cancer Institute, 450 Brookline Avenue, Boston, MA 02215, USA; ${ }^{6}$ Harvard Medical School, Department of Medicine, Boston, MA 02115, USA; ${ }^{7}$ International Breast Cancer Study Group Coordinating Center, Effingerstrasse 40, Bern CH-3008, Switzerland; ${ }^{8}$ Department of Medical Oncology, University Hospital of Udine, Piazzale S.M. Misericordia 15, Udine 33100, Italy; ${ }^{9}$ School of Medical Oncology, The University of Udine, Udine 33100, Italy; ${ }^{10}$ Vall $d^{\prime \prime H e b r o n}$ Institute of Oncology (VHIO) and Vall d'Hebron University Hospital, Barcelona 08035, Spain; ${ }^{11} \mathrm{SOLTI}$ Group, Barcelona 08008, Spain; ${ }^{12}$ CRO Aviano, IRCCS, National Cancer Institute, Via F. Gallini 2, Aviano 33081, Italy; ${ }^{13}$ Department of Oncology, Institute of Clinical Sciences, Sahlgrenska Academy, University of Gothenburg, Sahlgrenska University Hospital, Röda stråket 16, Gothenburg 413 45, Sweden; ${ }^{14}$ Monter Cancer Center of the North Shore-LIJ Health System, 450 Lakeville Road, Lake Success, NY 11042, USA; ${ }^{15}$ NRG Oncology, Four Penn Center, 1600 JFK Blvd, Suite 1020, Philadelphia, PA 19103, USA; ${ }^{16}$ Department of Oncology, Breast Center CHUV, Rue du Bugnon 46, Lausanne 1011, Switzerland; ${ }^{17}$ Tweed Heads Hospital, Tweed Heads, Griffith University, Gold Coast, Powell Street, Tweed Heads, NSW 2485, Australia; ${ }^{18}$ Abramson Cancer Center, University of Pennsylvania, Philadelphia, PA 19104, USA; ${ }^{19}$ ECOG-ACRIN, 1818 Market Street, Suite 1100, Philadelphia, PA 19103, USA; ${ }^{20}$ Frontier Science and Technology Research Foundation; ${ }^{21}$ University of Sydney, Sydney, NSW 2006, Australia; ${ }^{22}$ Harvard T.H. Chan School of Public Health, Department of Biostatistics, Boston, MA 02115, USA; ${ }^{23}$ Cogstate Ltd, 2/255 Bourke Street, Melbourne, VIC 3000, Australia; ${ }^{24}$ Mater Hospital, 40 Rocklands Road, North Sydney, NSW 2060, Australia; ${ }^{25}$ University of Newcastle, Calvary Mater Newcastle Hospital, Australia; ${ }^{26}$ Australia and New Zealand Breast Cancer Trials Group (ANZBCTG), NBN Telethon Mater Institute, Locked Bag 7 HRMC, Newcastle, NSW 2298, Australia; ${ }^{27}$ Department of Psychiatry and Behavioral Sciences, Memorial Sloan-Kettering Cancer Center, 641 Lexington Ave FI 7, New York, NY 10022, USA; ${ }^{28}$ Alliance for Clinical Trials in Oncology, Chicago, IL 60637, USA; ${ }^{29}$ The University of Chicago Medical Center, 5841 South Maryland Ave, MC 2115, Chicago, IL 60637, USA and ${ }^{30}$ Inselspital, Bern University Hospital, Bern CH-3010, Switzerland 